\title{
The Learning Motivation and Understanding towards Programming Education of Elementary School Students in Japan
}

\author{
H. Kanoh
}

\begin{abstract}
Programming education through visual programming language has been introduced in many elementary schools. And lately, the number of robots for programming keeps increasing. It is becoming pervasive to see elementary school kids to construct their own robots, then make them move by the visual language programming. Undoubtedly it is essential to measure students' learning motivation and degree of understanding towards robot programming through visual language itself before implementing it in various subjects as a general academic routine. The methodology is conduct the class for the robot programming to elementary school kids, and after that a question paper investigation was conducted. And in our measurement, we found that by programming, both the learning motivation and the degree of understanding have tremendously increased. Thus, our hypothesis is, if students' learning motivation and understanding decrease when programming education is applied in different subjects, the teaching curriculums should be revised.
\end{abstract}

Index Terms-Programming, robot, visual programming language, robot programming.

\section{INTRODUCTION}

\section{A. Penetration of Robot Programing}

Computer is becoming a necessity in our daily lives, individual users make use of it in particular personalized ways and 'programming by end-users 'is no longer a far and impossible idea. In recent years, we have witnessed the increasing number of AI robots reporting news, weather forecast, talking, dancing, and providing quiz games. Besides, starting with the exploitation of Nao in 2005 by Aldebaran Robotics, a company based on Paris, France, there are more AI robots which can recognize human faces and do chit-chat with us like PALRO by Fujisoft in 2010, Palmi by DMM and Pepper released in 2014. They talk and dance, following all commands from cellphones or tablets. Indeed, this feature makes them highly applicable in education for kids.

On the other hand, robots for educational purposes also come with a smaller size and in a low-cost market, such as the Wonder Workshop Dash Robot, Ozobot, SPHERO, BB-8, Wow Wee COJI The Coding Robot Toy, mBot, Transformable DIY Programmable Robot Kit, Clementoni My First Robot, LEGO, Bocco, Plen, Chip, Damian, Hicolor, Kamigami Robots Spot the Ladybug, DOBBY, Robi, Robohon, Roboactor, OHaNAS, Zoomer, Mip, KINGBOT,

Manuscript received November 27, 2017; revised June 14, 2018.

H. K. Author is with the Yamagata University, Institute of Arts and Sciences, Yamagata, Japan (e-mail: kanoh@pbd.kj.yamagata-u.ac.jp).
DIY Iron Bot Robot, Premaid, light sensor programing car, the exhilarated robot programming set, the Puchi little robot, block robot taste and Tama robot, etc (PALRO, DMM...etc, these are proper nouns not an abbreviation).

Why are there so many robots invented for programming education? In fact, in many countries like the UK, Estonia and Spain, computer studies are implemented as compulsory education in elementary schools for kids as small as five. When visiting the schools in these countries, we see students even in low grades learn about programming as an obligatory curriculum. And when we looked into the matter why robot programing is implemented we received answers saying robot programming has an amazing enhancing effect to improve students' motivation to learn as it stimulates not only though a computerized screen but by its actual movements. Especially in Spain, it is not difficult to see robots designed for 5 -year-old or 6-year-old kids. In this sense, Spain is in a very advanced phase in the formulation of programing robots.

Moreover, they stimulate students through body sensation. In prior to the breakthrough learning point at 9 years old, touching various objects and observing in real objects are vitally important [1].

Considering these inspiring facts, our focus is on the planning of the implementation of robot programming as elementary students in Japan, in where programming education is still in a very initial stage, Japanese students should also be more interested in programming through real and visible robotic movements than in computerized ones.

The learning motivation of elementary school students depends on the type of robot used, while Hirama and his group proved that robots generally increase students' motivation to learn [2]. While there are investigations on emotion-quantifying questions like whether students enjoy robot programming, whether they are interested and whether they want to do that again, the degree of understanding towards the construction of the robot and programming have not yet been measured.

In 2012, Fukaya and Miyaji made use of a visual programming language learning material called "PUROGURAMIN" to quantify students' emotions, and the result reflects high index values and hence it showed students' positive perception of it [3].

\section{B. The Introduction of Programming Education in Japan}

Programming is considered as literacy and the foundation ability of all. It refers to the ability to plan and model all the necessary intermediate steps to achieve a certain goal without mastering specialized programming language or memorizing source codes. And the direction has already been introduced 
as early as in April 1996 by the working group of the united information-related education project committee from the Japan Society for Education Technology in their special report "Proposal about the teaching and learning focus of the information-related education in elementary, junior high and high schools" (The working group of the united information-related education project committee from the Japan Society for Education Technology in 1996) [4].

At that time, there were discussions on whether programing should be introduced as a separate subject in elementary school, or should it be merged into existing subjects as ways to perceive and think; and also on whether it should be incorporated in the general learning time [5], [6]. Afterward, Iguchi has also suggested a cross curriculum with three axes on ability to utilize information, subject, and school grade \& development (see Fig. 1) [7].

In a macro point of view there is a greater number of countries implement programming as a separate subject, while the Ministry of Education in Japan decided, in March 2017 , in the amendment of the learning \& instruction focus in Japan (to be enforced in 2020) that programming should be incorporated in various subjects.

Certainly, the merits like the synergy effect of implementing programming education together with other subjects are constantly reported [8]-[11].

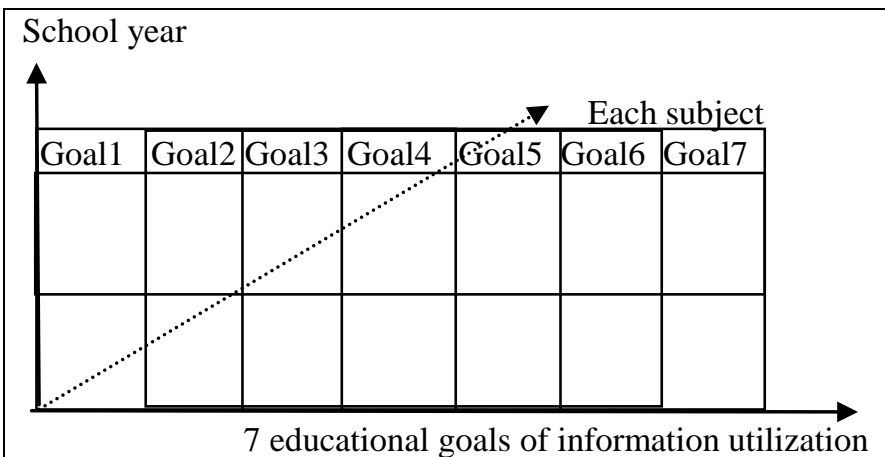

Fig. 1. The Cross-curriculum with 3 -axis (Iguchi, 1997). ※The original figure is Japanese, so re-making it.

Nevertheless, let say, student A \& B are now trying to solve a math word-question about function through programming. Student A is very good at programming but got bogged in the understanding of the function; and B can't do programming at all while with a sheet of paper and a pencil, concepts about function are written perfectly and problems are solved. Without a shadow of doubt, B acquires a higher score in this Math class. So how would A, who worked hard to master programming, feel?

It is also believed that programming, once the foundation being learnt and mastered, the concept is applicable in various subjects. Yet, in a stage that notions about programming remain unclear and assessment is only done on whether the ideas of that academic subject are mastered, then why should programming be implemented? Why should students think through it? It still remains as a confusing question for the front liners, both teachers and students, in education.

\section{OVERVIEW OF PROGRAMMING EDUCATION}

\section{A. Theories of Visual Development \& Programming Education}

As described in the well-known development theories, the genetic epistemology of Piaget, J., human's cognition is divided into system epistemology, individual epistemology, or both. And there are four developmental phases.

Phase 1 Feeling; movement period

Phase 2 Pre-control period

Phase 3 Concrete control period

Phase 4 Format control period

The approach to think and learn differs from each other in these four phases, and 4 main concepts are upheld in these developmental phases.

- schema

- assimilation / accommodation

- equilibration

- operation

First, the schema in phase 1 is like the robot smiles when the controller pets it; and it moves forward when the controller chooses the block for proceeding forward. It is a phase in which the existence of the controller is highly recognized.

And in phase 2, the pre-control period, when the controller gives out a command of moving three blocks forward, and doing a 90-degree rotation after proceeding $20 \mathrm{~cm}$, the robot can follow the command by calculating how much it should proceed in one second with the recognition that the material of the floor affects the moving speed and thus it automatically calculates and creates its own schema by synchronizing and adjustment.

The $3^{\text {rd }}$ phase in elementary school is the concrete control period, in this through the control experiments like transferring water in different forms, students acquire the concepts the conservation of substance amount (at the age of 8), conservation of weight (age of 9) and then volume (age of 11). And importantly at this phase, programming robot is appropriate for programming education. Here through concrete objects, students learn to think about the content of the programming for the robot to reach and stop just right at the goal without colliding with any obstacles. The programming robot suggested in this article is, indeed, most applicable in the programming education in this concrete control period.

The last phase, the format controlling period falls in junior high school time and here abstract concepts are put into control, and the analyzing process goes smooth without aid of concrete objects. Multiple commands can be processed at the same time, and commands with multiple interpretation can be analyzed, and hence, programming can be applied through computer.

\section{B. Visual Programming Language and Robot Learning Material}

Visual programming language refers to the programming language through visual control and without any description of programming codes.

The most penetrated and widely used one is "Scratch", developed in 2006 by Professor Mitchel Resnick from MIT Media Laboratory of Massachusetts Institute of Technology [12]. Very much similar with "Scratch", "Stencyl" can also 
process programming without any use of codes and it provides a beloved platform for kids to create their own cell phone mini games. "MOONBlock" is another excellent model which can display block-made contents in JavaScript code. The earlier mentioned "PUROGURAMIN" by the Ministry of Education in Japan process programming through the combination of some prepared pictures, and thus let small kids experience what programming is like. Also, "VISCUIT", developed by Yasunori Harada from NTT research laboratory make programming learning available by moving hand-drawn pictures. Finally, an OS combined programming learning world is provided by "KANO world" that users can do programming to combine music, camera, Google map or even self-made images, animation, or movie applications without any use of code when the it's all clear since the training mode.

The programming in this paper refers to the programming software "Procon tracer command program Ver. 1.1" by ArTec and the robot learning material is the programming robot (ArTec) of the "Analysis \& Command by BT information-related program". The operation of the programming robot is shown in Fig. 2.

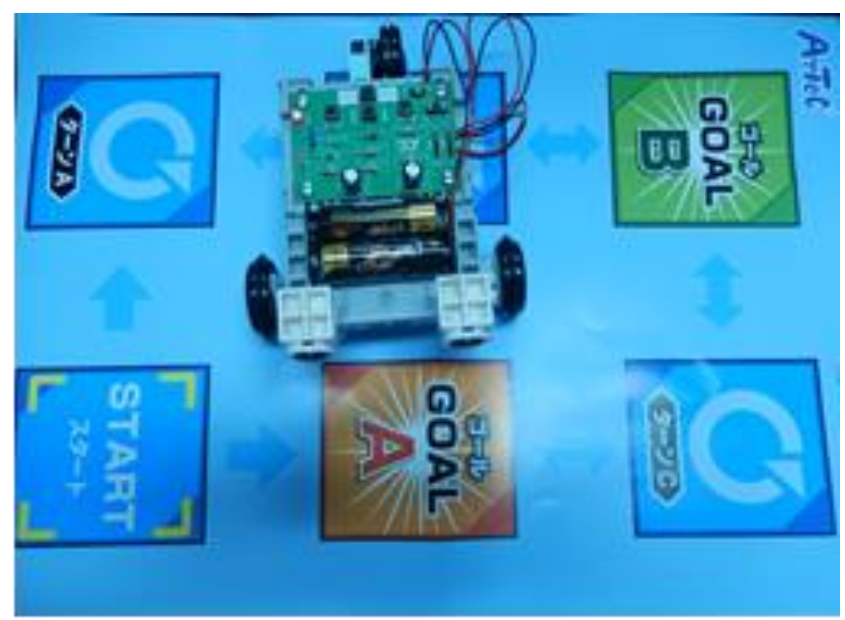

Fig. 2. Operation of the programming robot.

\section{Aim of the Class}

The objective of carrying out programming education is to nurture ways to think and learn, i.e. by using the learning material, students experience the Plan-Do-See learning cycle by planning how to make the robot move, putting ideas into actions and as problem-solving solutions, and eventually undertake self-evaluation at the end. The learning here does not merely stop on the skills and robot-control level, but also transcend to the development of problem-solving, critical, logical, and creative thinking. We strongly believe that such important knowledge can applied as students' life skill and life-long knowledge.

\section{OBJECTIVE AND Methodology OF RESEARCH}

Kanoh [13] upholds the instruction proposal of nurturing "ways to learn and think about the information" defined by Kanoh and her group [14], [15], and the implementation of the programming education proposal in the concrete controlling period of Piaget, J's development theory is also suggested. The research in this paper can be considered as the report of the result of such a continued further study of the proposals, and as a realization of robot programming to elementary school kids [16].

The project 'Exciting and Heart-beating Science' was carried out on 5th August 2016 (Fri) at Yamagata University. 80 applications were received from students in elementary grade $5 \& 6$, and 56 early applicants were selected ( 44 boys \& 8 girls; 27 grade $5 \& 25$ grade 6 students). A lecture about humanoid robot \& information literacy suggested by Kanoh [14] was held in the morning, which including singing, dancing, and quiz game performance form the human robot. It was then followed by a chit-chat session between the robot and the kids. In the afternoon, the robot programming session as being described below was held.

According to Taira et al. [2] and Fukaya \& Miyaji [3] programming and robot programming by visual programming language greatly motivate kids to learn.

Yet, it is believed that kids will say they are having fun no matter they understand the content or not, and thus besides the measurement of the emotional aspects, the degree of understanding is also measured. This is simply the essence of the research.

The methodology is as described below; we follow the lesson plan and conduct the class, and after that a question paper investigation was conducted (see as Table I).

TABLE I: ROBOT PROGRAMING INSTRUCTION (KANOH, 2016)

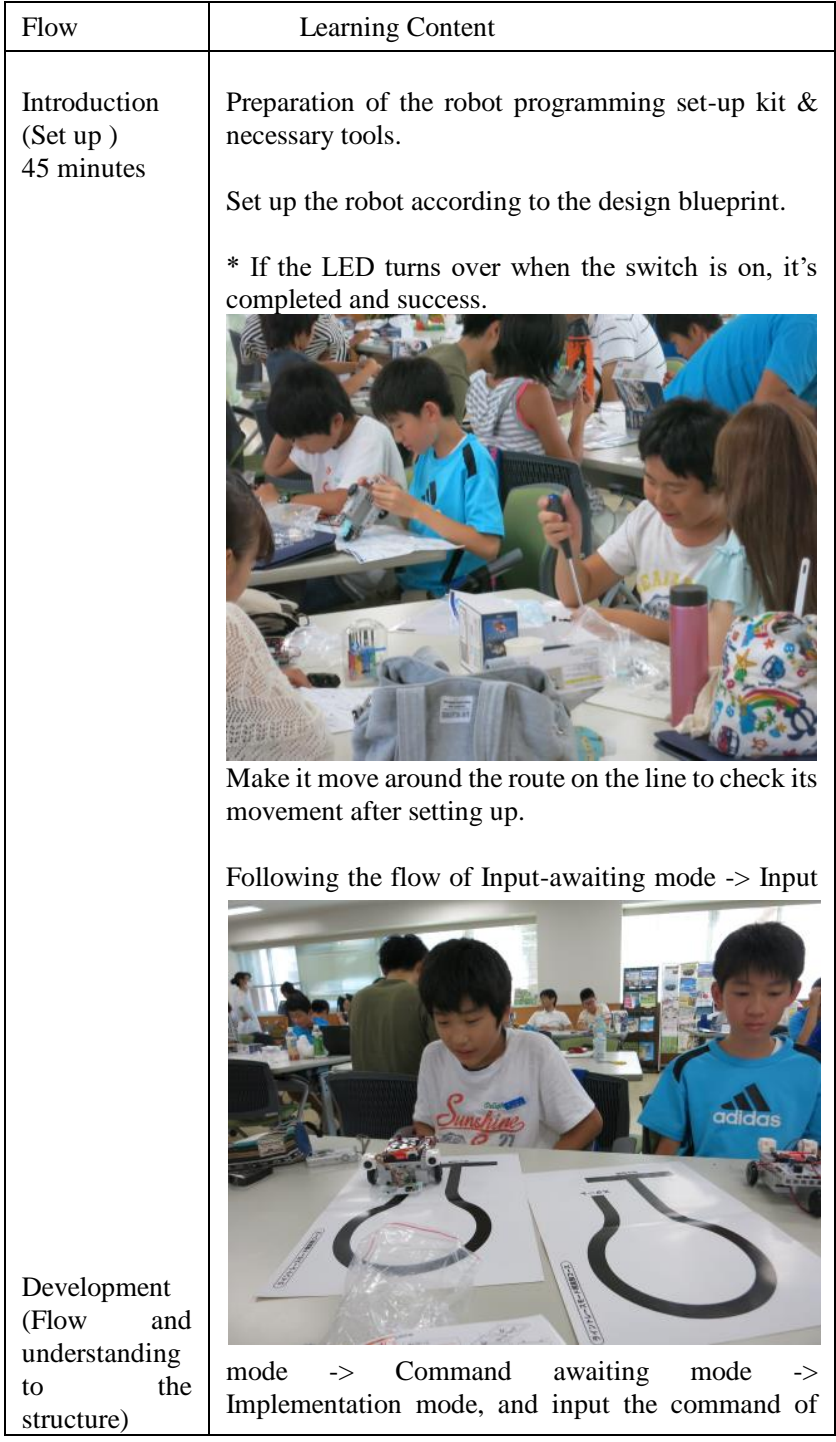




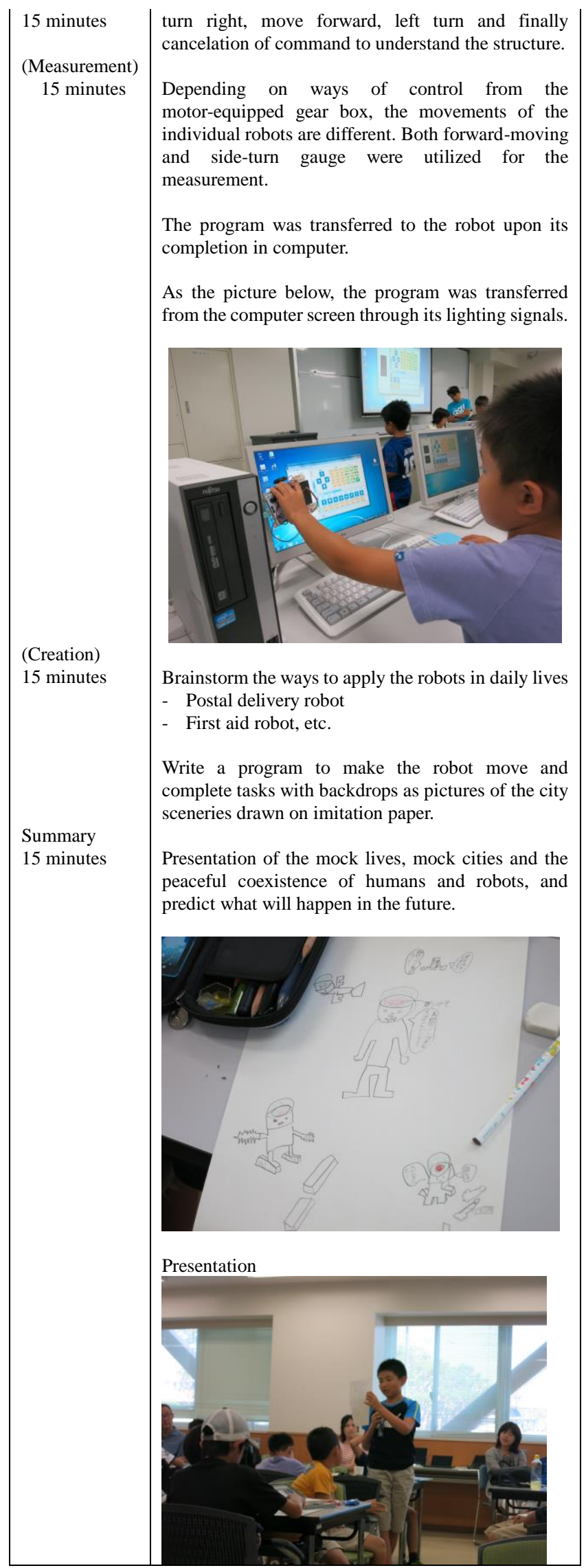

The teaching materials used is the ArTec programming robot of the "Analysis \& Command by BT information-related program". Fig. 3 shows a screen caption of the Procon Tracer programming.

A question paper investigation was held afterwards, and the questions are as below,
Q Circle the number about a society well embraced the technology of humanoid robots (6-level ranking)

Looking Forward/Not Looking Forward; Reliving/ Anxious; Health/Unhealthy; Economical/uneconomical; Preferred /Not preferred; Exciting /Boring; Attractive /Not Attractive; Continuous/Non-continuous; Penetrating/ Deteriorating; Realistic/Unrealistic, realistic unrealistic

Q About today's learning (6-level ranking)

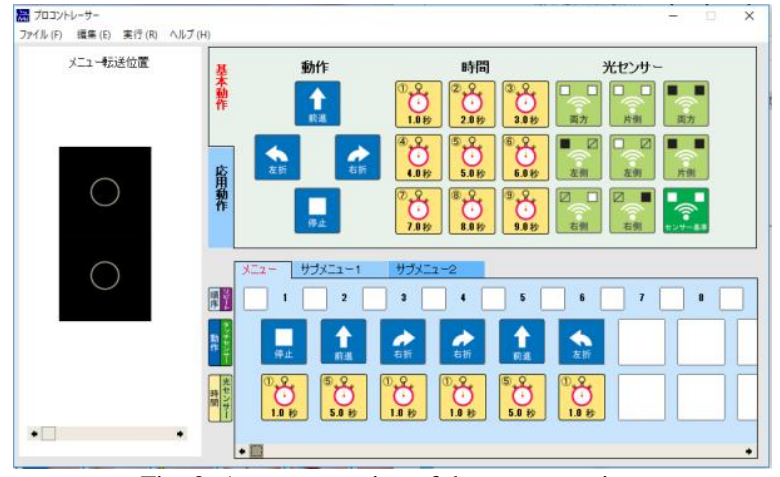

Fig. 3. A screen caption of the programming.

\section{RESULT}

\section{A. Setting up the Robot and Understanding the Programing}

When checking the Pearson correlation coefficient on both sides, a highly positive correlation coefficient $(r=.801, p<.01)$ was found about the degree of understanding to the robot set-up and the programming itself. The linear approximation curve is $y=0.825 x+0.7451$, which proves that kids who have higher degree of understanding to the setup also understanding the programming better. And the distribution is shown in Fig. 4.

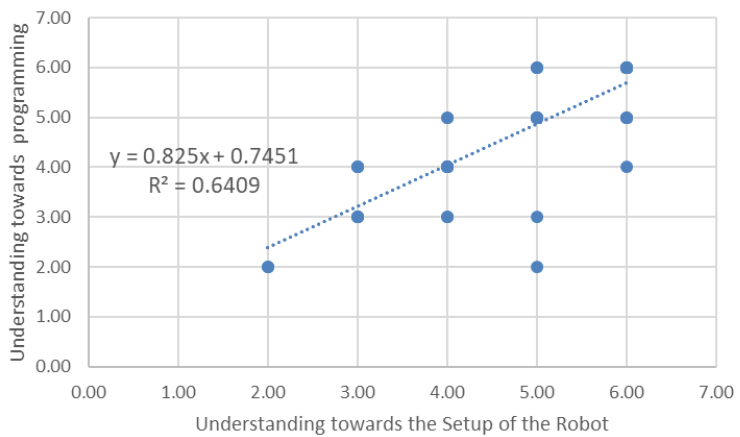

Fig. 4. Degree of understanding towards the setup of the robot and programming.

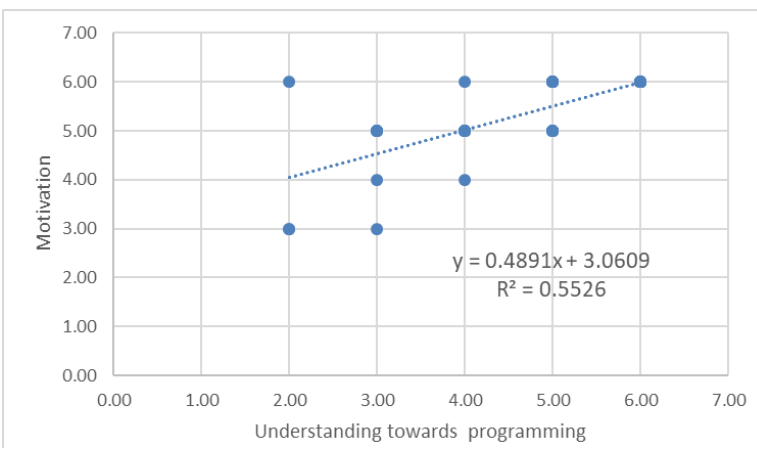

Fig. 5. Learning motivation and degree of understanding towards programming. 


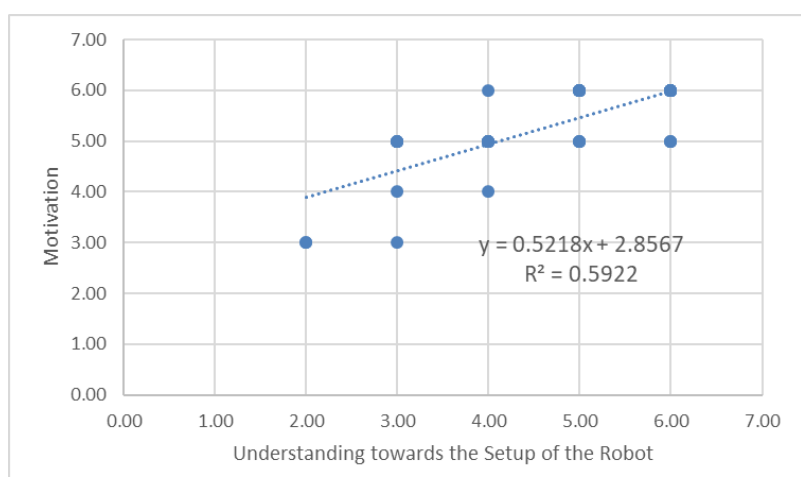

Fig. 6. Learning motivation and degree of understanding towards robot setup.

\section{B. Learning Motivation and Degree of Understanding towards Programming}

When checking the Pearson correlation coefficient on both sides, a highly positive correlation coefficient $(r=.743, p<.01)$ was found about the degree of understanding to the programming itself. The linear approximation curve is $y=$ $0.4891 x+3.0609$. Though not as steep as the Fig. about both the programming and the robot setup, it still proves that kids are highly motivated to learn about and have a high degree of understanding towards programming. And the distribution is shown in Fig. 5.

\section{Learning Motivation and Degree of Understanding towards Robot Setup}

As for the learning motivation and understanding of the robot setup, a highly positive correlation coefficient ( $r=.770$, $p<.01$ ) was also found when checking the Pearson correlation coefficient on both sides. The linear approximation curve is $y$ $=0.5218 x+2.8567$, and it illustrates that kids are highly motivated to learn and understand about the robot setup (Fig. $6)$.

\section{Understanding and Expectation towards Robot Setup}

Fairly high positive correlation coefficients are found when we look at the understanding towards robot set up and expectation to see robots playing on the global stage $(r=.532$, $p<.01)$. The linear approximation curve is $y=0.6246 x+$ 2.324. In other words, kids understand well about robot setup, and they do look forward to seeing great development and higher penetration of robots in our future daily lives (Fig. 7).

\section{E. Understanding and Expectation towards Programming}

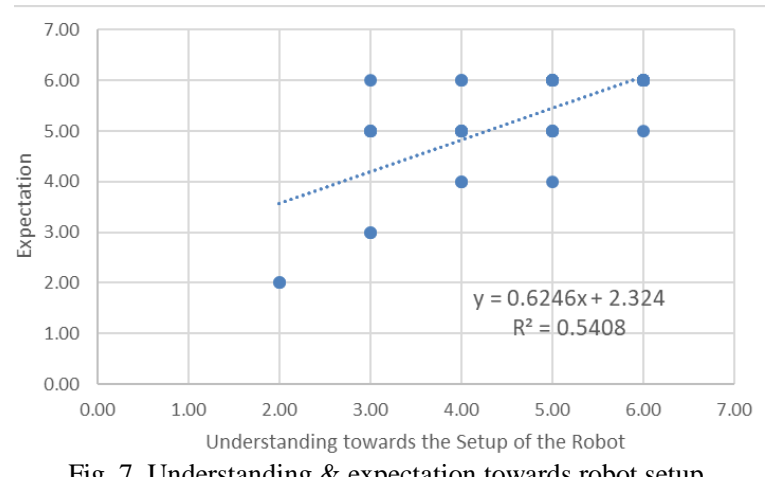

Fig. 7. Understanding \& expectation towards robot setup.

Again, a fairly high positive correlation coefficient is found when we look at the understanding towards programming and expectation to see greater development of it $(r=.555, p<.01)$. The linear approximation curve is $\mathrm{y}=0.5835 \mathrm{x}+2.5779$. Here again in other words, kids understand well about programming, and they do look forward to seeing great development and higher penetration of it in the future (Fig. 8).

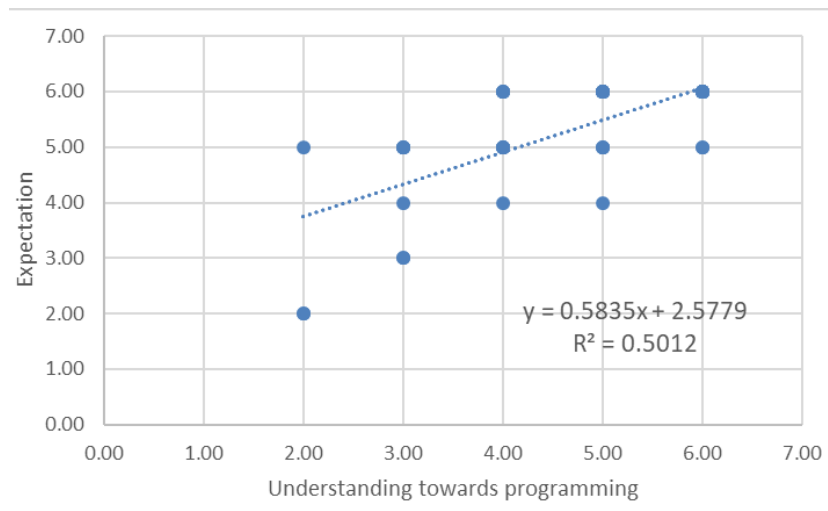

Fig. 8. Understanding \& expectation towards programming.

\section{F. Motivation and Expectation}

A fairly high positive correlation coefficient value is noted when we look at the overall motivation and expectation towards programming and robot setup $(r=.624, p<.01)$. The linear approximation curve is $y=1.0802 x-0.4687$. Kids are simply eager to learn more about programming (Fig. 9).

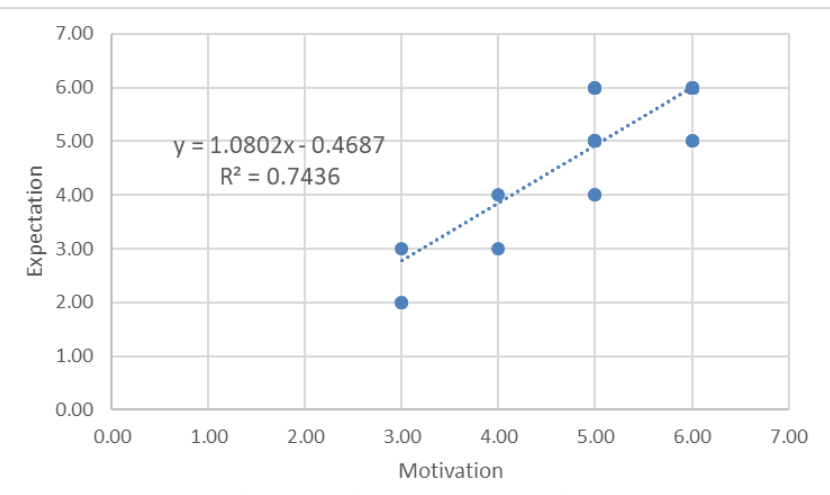

Fig. 9. Motivation \& expectation.

\section{G. Continuous Learning Motivation and Expectation}

When checking whether kids want to do robot setup and programming again, we again witness A fairly high positive correlation coefficient value of $(r=.579, p<.01)$. Overall, kids are willing to continue to learn more about programming and do look forward to seeing it happens soon.

\section{EXAMINATION}

In the above research, we make use of the self-setup robot from ArTec to measure elementary school kids' understanding and motivation towards robot set up and programming. And in the result, we found that the kids are both motivated and well understand the programming as well as the setup. The details like the learning materials and instruction flow are different from those of the Taira et al. [2], but the result about student's high motivation and high degree of understanding match up. And here in our research, we successfully proved that students do not merely enjoy the 
process for fun but also showed a high degree of understanding towards the learning content.

As mentioned earlier in the paper, since students enjoy and understand programming and making up robots, so in the future when we incorporate robot making or programming in existing subjects, it is the curriculums of these subjects that have to been amended if students lose their learning interest or perform worse.

\section{REFERENCES}

[1] H. Kanoh, "An analysis from the learning history figure of the natural exploration of learning - The extension of the autopoiesis thesis," Bulletin of the Association of Education Goals \& Assessment, vol. 19, pp. 57-66, December 2009.

[2] K. Taira et al., "Programming study using robot teaching materials in elementary school," The Technology in Education, Utsunomiya University bulletin of the Integrated Research Center for Educational Practice, vol. 37, pp. 141-148, July 2014.

[3] K. Fukaya and A. Miyachi, "A study on the utilization of "programin" for programming lessons for elementary school students," Japan Journal of Educational Technology, vol. 36, pp. 511-516, March 2012.

[4] Information-related Education Project Committee Working Group of the Japan Society for Educational Technology. (April 1996). A Proposal about the Learning \& Instruction Focus in elementary, junior high and high schools. [Online]. Available: http://kayoo.org/nagano/Activity/stk-jyohou/01.htm

[5] T. Mizukoshi, "Talks about the curriculum of information education," presented at the Japan Society for Educational Technology Symposium, June 1996.

[6] I. Iguchi, "Daily leaning selection from "information education teaching curriculum in elementary school," A Proposal to the Reform of Curriculum, Looking forward in the 21st Century, Tokyo: Japan Science Support Foundation, 1996, pp355-362.

[7] I. Iguchi, "The curriculum of information education in elementary school," Annual Academic Papers Collection from Japan Society for Science Education, vol. 21, pp. 201-202, 1997.

[8] K. Kihara, "Instruction in integrated subjects of lower elementary school grades," Modern Education of Science, vol. 20, no. 2, pp. 100-103, 1977

[9] T. Yamato, "Instruction of the integrated subjects in lower grades," Japan Society of Mathematical Education Journals, vol. 63, no. 10, pp. 217-219, 1981
[10] I. Suda, T. Tajima, and T. Tamaki, "Trial I of typology of integrated research in Japan," Japan Curriculum Research and Development Association Journals, vol. 7, no. 4, pp. 197-204, 1982.

[11] M. Murakawa, "Current situation \& challenges in the foundation of school curriculum (II): A focus on integrated learning in lower grades in elementary school," Naruto University of Education Research Overview, Education Science, Naruto University of Education, vol. 3, pp. 19-35, 1988.

[12] S. Schorow, "Creating from scratch new software from the MIT media lab unleashes kids' creativity online," News Office Correspondent, May 14, 2007.

[13] H. Kanoh, "The proposal about programming education through robots for nurturing ways to think and learn based on Piaget, J's development theories," The Japan Society of Science Education 40th Annual Journal Selections, pp. 241-242, August 2016.

[14] H. Kanoh, T. Hishida, M. Hasegawa, and K. Kozaki, "An analysis of the information-related language in high school, Ministry of Education Japan Approved Textbook Series," The Japan Society of Science Education 37th Annual Journal Selections, pp. 152-155, September 2013.

[15] H. Kanoh, T. Hishida, M. Hasegawa, and K. Kozaki, "Information literary (focusing on information analysis) construction of ontology," The Japan Society of Science Education 38th Annual Journal Selections, pp. 101-104, September 2014.

[16] H. Kanoh, "The proposals \& challenges of information education through humanoid robots," The Japan Society of Science Education 39th Annual Journal Selections, pp. 344-345, August 2015.

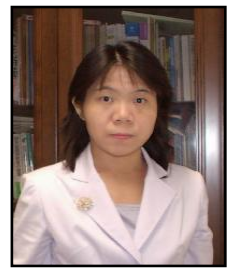

Hiroko Kanoh was born in Japan. She has been as an associate professor in the Institute of Arts and Sciences National University Corporation Yamagata University, Yamagata prefecture in japan. Her areas of specialization are educational technology, cyber psychology and ICT education. Shi has more than 20 international and 100 national publications and 30 authored books - 'Structure and prevention of Cyber bullying (Tokyo, Japan: Kaneko Shobo, 2016)', 'Children of immediate response syndrome (Tokyo, Japan: Japan Standard, 2009)', 'Information Society (Kyoto, Japan: Kitaooji Shobo, 2007)', The Reason for Indiscriminate Murder Occurs (Tokyo, Japan: Japan Standard, 2008)' and so forth. She has been awarded the Culture, Sports, Science and Technology Minister's Commendation of the field of science and technology in 2010. She graduated from the master's program Tokyo Gakugei University, Tokyo in Japan through the doctoral program at Waseda University, Tokyo in Japan. She is now working as an associate professor in the Institute of Arts and Sciences National University Corporation Yamagata University, Yamagata prefecture in Japan. 